\title{
Evolução Cicatricial de feridas Crônicas no Uso de Plasma Rico em Plaquetas: série de casos
}

\section{Healing Evolution of Chronic Wounds in the Use of Platelet-Rich Plasma: series of cases}

\author{
Natália dos Santos Freitas Maues ${ }^{1}$ \\ Bruna Maiara Ferreira Barreto Pires ${ }^{2}$ \\ Beatriz Guitton Renaud Baptista de Oliveira ${ }^{3}$ \\ Hye Chung Kang 4 \\ Marilda Andrade ${ }^{5}$ \\ Jane Marcy Neffá Pinto ${ }^{6}$ \\ Pedro Henrique de Carvalho Rodrigues ${ }^{7}$
}

\footnotetext{
${ }^{1}$ Enfermeira. Especialista em Enfermagem Saúde Coletiva e Mestranda em Ciências do Cuidado em Saúde pela Escola de Enfermagem Aurora Afonso Costa (EEAAC), Universidade Federal Fluminense (UFF). RJ, Brasil. E-mail: natifreeitas@gmail.com. Autor correspondente.

²Enfermeira. Doutora e Mestre em Ciências do Cuidado em Saúde pela Escola de Enfermagem Aurora Afonso Costa (EEAAC), Universidade Federal Fluminense (UFF). RJ, Brasil. E-mail: bruna.barreto@gmail.com.

${ }^{3}$ Enfermeira. Doutora em Enfermagem. Professora Titular da EEAAC/UFF. RJ, Brasil. E-mail: beatrizguitton@globo.com.

${ }^{4}$ Farmacêutica. Doutora em Enfermagem. Professora Titular da EEAAC/UFF. RJ, Brasil. E-mail: hyekang@id.uff.br.

${ }^{5}$ Enfermeira. Doutora em Enfermagem. Vice-Diretora e Professora Associada da EEAAC/UFF. RJ, Brasil. E-mail: marildaandrade@uol.com.br.
}

${ }^{6}$ Médica. Doutora em Dermatologia. Professora Titular de Dermatologia, do Departamento de Medicina Clínica da Faculdade de Medicina da UFF. RJ, Brasil. E-mail: janenaffa@gmail.com.

${ }^{7}$ Médico. Especialista em Cirurgia Geral e Residente em Urologia no Hospital Universitário Gafrée Guinle (HUGG/UNIRIO). RJ, Brasil. E-mail: phcr@hotmail.com. 


\section{Resumo}

Objetiva-se avaliar a efetividade do Plasma Rico em Plaquetas (PRP) no processo de cicatrização de feridas crônicas. Trata-se de um estudo de série de casos. Desfechos primários: percentual de feridas cicatrizadas; taxa de redução da área das feridas. Desfechos secundários: alteração do tecido no leito das feridas; quantidade de exsudato da lesão, odor e dor. Os dados foram coletados entre os meses de novembro de 2013 a março de 2014, com tempo de seguimento de 12 semanas. O procedimento de coleta de dados foi realizado em três etapas: anamnese, coleta e tratamento do sangue e a realização do curativo com utilização do PRP. A amostra foi composta por 5 pacientes com úlceras de perna. Houve uma ferida completamente cicatrizada e as demais feridas apresentaram taxa de redução da área de 34\%, 30\%, 12\% e 11\%. Conclui-se que o PRP favoreceu o processo de reparo tecidual.

Palavras-chave: Ferimentos e Lesões; Cicatrização; Fator de Crescimento Derivado de Plaquetas.

\section{Abstract}

The aim of this study was to evaluate the effectiveness of Platelet-Rich Plasma (PRP) in the healing process of chronic wounds. This is a cases series study. Primary outcomes: percentage of healed wounds; reduction rate of the wound area. Secondary outcomes: alteration of tissue in the wound bed; amount of exudate from the wound, odor and pain. Data were collected from November 2013 to March 2014, with a follow-up time of 12 weeks. The data collection procedure was performed in three stages: anamnesis, blood collection and treatment and dressing using PRP. The sample consisted of 5 patients with leg ulcers. There was a completely healed wound and the remaining wounds presented an area reduction rate of $34 \%, 30 \%, 12 \%$ and $11 \%$. It is concluded that PRP favored the tissue repair process.

Keywords: Injury and Wounds; Healing; Growth Factor Derived from Platelets. 


\section{Introdução}

Ferida crônica é a lesão cujo processo de cicatrização não ocorreu no prazo de 12 semanas ${ }^{(1)}$. A úlcera é o termo usado para se referir a feridas espontâneas ou traumáticas, geralmente nas extremidades inferiores, que não cicatrizam em um prazo razoável, com uma etiologia subjacente que pode estar relacionada com a doença sistêmica ou distúrbios locais ${ }^{(2)}$.

A úlcera crônica tem grande impacto na qualidade de vida dos pacientes e nos custos de saúde pública no Brasil e no mundo, é considerada um problema grave e de abrangência mundial. Entre as feridas de membros inferiores, as vasculogênicas são as mais prevalentes, caracterizando-se por um processo crônico, doloroso, recorrente, com impacto negativo na qualidade de vida, na mobilidade, no estado emocional e na capacidade funcional das pessoas acometidas ${ }^{(3)}$.

Além disso, a preocupação com o custo do tratamento das úlceras é global, pois possui grande repercussão na qualidade de vida do indivíduo e é uma fonte adicional de despesas, devido ao custo do tratamento farmacológico e dos produtos para realização do curativo, afetando o equilíbrio financeiro da família, com implicações psicológicas e sociais para o paciente $e^{(4)}$.

Logo, pode-se perceber que as úlceras crônicas causam um grande impacto social e econômico devido a sua natureza recorrente, e ao longo tempo decorrido entre a sua abertura e cicatrização.

As feridas crônicas requerem um longo tempo para cicatrizar e frequentemente apresentam recidivas. Mesmo quando manejadas corretamente as chances de recorrerem ou mesmo de nem fechar, são grandes, destacam-se alguns pacientes do nosso ambulatório que possuem úlceras com o tempo de evolução de até 42 anos. Devido a isso, o portador de úlceras crônicas necessita de tratamentos mais eficazes e mais baratos, como é o caso do Plasma Rico em Plaquetas - PRP(5).

Sabe-se que a restauração da pele ocorre por meio de um processo dinâmico, contínuo, complexo e interdependente, composto por uma série de fases sobrepostas, denominadas de cicatrização(6). O processo de cicatrização de feridas é complexo e desencadeia uma cascata organizativa e complexa de eventos celulares e bioquímicos.

Para tal, torna-se necessário favorecer condições locais através de terapia tópica adequada para viabilizar o processo fisiológico do reparo tecidual. Entre as diversas substâncias que podem ser utilizadas no tratamento das úlceras, encontra-se o Plasma Rico em Plaquetas (PRP) que é um produto derivado da centrifugação do sangue total, sendo rico em fatores de crescimento e proteínas estruturais ${ }^{(7)}$.

A liberação dos fatores de crescimento pelas plaquetas contidas no PRP pode favorecer a reparação das lesões, e possibilitar o mais rápido retorno à funcionalidade, possivelmente, por estimular a neovascularização, que melhora o suprimento sanguíneo e disponibiliza nutrientes necessários à regeneração tecidual ${ }^{(8-9)}$.

Assim, tornam-se necessários estudos que comprovem sua segurança, eficácia e efetividade, uma vez que o tratamento com o PRP é pouco custoso e desenvolve menos alergias por ser um processo autólogo, obtido através da centrifugação do sangue do próprio paciente. Talvez pelo fato de tratar-se de uma técnica de baixo custo de obtenção e preparo, e de fácil execução, não tenha despertado o interesse da indústria farmacêutica. Além disso, o uso do PRP autólogo demonstra ser uma alternativa importante nos casos em que tratamentos convencionais não foram bem sucedidos ${ }^{(10)}$.

Este estudo justifica-se pelo fato do PRP ser um tema que constitui uma técnica promissora, apresentando poucos estudos e alguns ainda muito limitados no que diz respeito à avaliação de sua eficácia. Uma vez que uma visão mais nítida da fisiologia da cicatrização resulta em uma compreensão maior acerca dos processos fisiopatológicos que dificultam a cicatrização. Esta pesquisa faz parte do projeto "Preparo de Plasma Rico em Plaquetas e sua aplicação no processo de cicatrização". A questão de pesquisa que orientou esse estudo foi: O PRP é um produto tópico efetivo na cicatrização de feridas crônicas? Dado o exposto, objetiva-se avaliar a efetividade do PRP no processo de cicatrização de feridas crônicas. 


\section{Método}

Estudo de série de casos com intervenção terapêutica do PRP em úlceras cutâneas, realizado no Ambulatório de Reparo de Feridas, do Hospital Universitário Antônio Pedro da Universidade Federal Fluminense (HUAP/UFF), localizado no térreo do HUAP.

A realização do curativo e a consulta de enfermagem foram prestadas por enfermeiros docentes, residentes de Saúde Coletiva e pósgraduandos. A Unidade atende a população cadastrada e pertencente à região adscrita. Desde então, constitui um centro de referência regional para o tratamento de pacientes com lesões crônicas, além de ser campo de ensino teóricoprático da disciplina de Fundamentos de Enfermagem I.

Os desfechos primários que foram observados no estudo são: percentual de feridas cicatrizadas e taxa de redução da área das feridas. Desfechos secundários: alteração do tecido no leito das feridas, exsudato da lesão, odor e dor.

A população do Ambulatório de Reparo de Feridas é predominantemente composta por idosos com doenças crônicas não transmissíveis, como: a insuficiência venosa crônica, hipertensão arterial e diabetes.

A amostra do estudo foi não probabilística, por conveniência composta por pacientes com úlceras de perna que atendessem aos critérios de inclusão e exclusão da pesquisa, que não obtiveram êxito com outras terapêuticas. Critérios de inclusão: ser maior de 18 anos sem distinção de sexo; apresentar feridas com tempo de evolução maior que 12 semanas; apresentar hematócrito $>34 \%$, hemoglobina $>11 \mathrm{~g} / \mathrm{dL}$ e contagem de plaquetas acima de $150.000 / \mathrm{mm}^{3}$ comprovados com hemograma com data retroativa de até 3 meses. Critérios de exclusão: estar grávida ou amamentando; possuir distúrbios de coagulação; apresentar alterações nos valores de normalidade nos exames de TAP e PTT; suspeita de malignidade da úlcera; alterações cognitivas; e apresentar irregularidades na frequência de comparecimento às consultas.

O procedimento de coleta de dados foi realizado em três etapas: Etapa 1 de Anamnese do paciente e preenchimento do protocolo I: para coleta de dados, foram utilizados instrumentos validados de uso do ambulatório contendo dados sociodemográficos e descritivos para avaliação do estado clínico do paciente e da lesão. No primeiro atendimento era realizado o screening dos participantes, preenchido o protocolo de primeira vez para avaliação dos pacientes e aplicado os critérios de inclusão. Posteriormente, para aqueles participantes selecionados, assinava-se o Termo de Consentimento Livre e Esclarecido (TCLE) e solicitava-se exames laboratoriais, tais como: hemograma completo, TAP, PT, creatinina, contagens de plaquetas, anti- HIV, anti- HBSAg, anti- HAV, anti- HCV.

$\mathrm{Na}$ Etapa 2 de coleta e manipulação/tratamento do sangue: realizava-se punção venosa com retirada de $20 \mathrm{ml}$ de sangue do paciente. Este sangue era coletado em 4 tubos com citrato de sódio a 3,2\% e posteriormente, as amostras eram submetidas à centrifugação durante 15 minutos, sob uma força de rotação de $1500 \mathrm{rpm}, \mathrm{a} 21^{\circ} \mathrm{C}$. Retirava-se o PRP da centrífuga, aspirava-se o PRP com a agulha 40x1,2 mm e adicionava-se, na mesma proporção, o Cloreto de Cálcio 0,025 mol/Litro, transformando o plasma em uma solução aquosa.

Na Etapa 3 de realização do curativo e utilização do PRP: durante o procedimento de realização do curativo, era retirado o curativo primário, realizada a lavagem com soro fisiológico e debridamento com pinça e bisturi. Após, aplicava-se o PRP na ferida, realizava-se cobertura com gaze IV e atadura crepom ${ }^{(13)}$. Quanto a planimetria e o registro fotográfico, eram realizados quinzenalmente para o acompanhamento do processo de reparação das lesões. Após 24 horas, os pacientes eram orientados a retirar o curativo e realizar curativo diário de acordo com o produto mais indicado, segundo as características clínicas das feridas.

Os dados da pesquisa foram tabulados e analisados com estatística descritiva simples e posteriormente discutidos. Foi realizado a frequência absoluta e porcentagem.

A análise das lesões foi realizada através do aplicativo Mowa', para avaliar a efetividade do tratamento empregado. Porém, o aplicativo apresenta limitação, uma vez que só avalia a face das lesões, por isso foi realizado também a planimetria das lesões. 
Esta pesquisa foi aprovada pelo Comitê de Ética em Pesquisa da Faculdade de Medicina/ Hospital Universitário Antônio Pedro, aprovada através do n.. 396/11 CAAE n.ㅇ 0412.0.258.00011.Os participantes assinaram o Termo de Consentimento Livre e Esclarecido (TCLE), atendendo a Resolução n.o 466/12 do Conselho Nacional de Saúde (CNS). As informações e o anonimato dos sujeitos envolvidos foram mantidos em sigilo pelo pesquisador, sendo de sua única responsabilidade, ressaltando-se que em qualquer momento foi garantida aos mesmos a possibilidade de se retirar do estudo.

\section{Resultados}

A amostra foi composta por cinco pacientes, sendo três mulheres e dois homens. Destes, três apresentavam úlceras venosas, um possuía úlcera em terço da perna referente a Síndrome Klippel-Trenaunay-Weber (SKTW) e um apresentava úlcera crônica no calcanhar, após tentativa frustrada de aplicação de enxerto de pele. O tempo de seguimento foi de 90 dias, perfazendo um total de 30 consultas. Os pacientes eram atendidos uma vez por semana, com mensuração das lesões e registro fotográfico realizados a cada 15 dias.

Os resultados são apresentados em duas categorias: Perfil sociodemográfico e clínico dos pacientes e Evolução das úlceras em tratamento com PRP.

\section{pacientes}

Perfil sociodemográfico e clínico dos

A análise das características sociodemográficas dos participantes da pesquisa permite descrever que a maioria (3) é do sexo femininoepossui faixa etária entre 60 e 70 anos (4).Há predominância de voluntários que possuem o nível superior (3), seguidos de ensino fundamental (1) e ensino médio (1). Quanto ao estado civil, a maioria(3) dos participantes era casada, ativa e possuía vínculo empregatício. Dois participantes são aposentados.

Percebe-se também que dois voluntários (40,00\%) possuem somente Hipertensão Arterial Sistêmica (HAS) e dois $(40,0 \%)$ possuem Insuficiência Venosa Crônica (IVC) e Hipertensão
Arterial Sistólica (HAS) e um $(20,00 \%)$ possui somente IVC.

\section{Evolução das úlceras em tratamento com} PRP

Foram estudadas cinco lesões, sendo três localizadas no maléolo, uma em terços da perna com tempo de evolução de mais de 10 anos e as quatro lesões apresentavam recidivas. Outro voluntáro apresentava uma lesão no calcâneo de origem traumática e tempo de evolução de 5 meses. 
Tabela 1. Evolução das úlceras da perna ao longo de 90 dias, em tratamento com o Plasma Rico em Plaquetas. Niterói, RJ, Brasil, 2014.

\begin{tabular}{ccccccc}
\hline \multicolumn{7}{c}{ Evolução em cm cmas lesões $^{2}$} \\
\hline Lesão & D1 & D30 & D60 & D90 & $\begin{array}{c}\text { Alteração em } \\
\text { cm }^{2}\end{array}$ & Alteração em \% \\
\hline Lesão 1 & 50,00 & 49,00 & 47,00 & 44,00 & $-6,00$ & Redução de 12 \\
\hline Lesão 2 & 38,00 & 30,00 & 28,00 & 25,00 & $-13,00$ & Redução de 34 \\
\hline Lesão 3 & 339,00 & 300,00 & 250,00 & 234,00 & $-105,00$ & Redução de 30 \\
\hline Lesão 4 & 43,00 & 40,00 & 38,00 & 38,00 & -5 & Redução de 11 \\
\hline Lesão 5 & 2,00 & 1,00 & 0,50 & $\begin{array}{c}\text { Cicatrizou } \\
\text { com 90 dias }\end{array}$ & -2 & Redução de 100 \\
\hline
\end{tabular}

Fonte: dados da pesquisa.

A Tabela 1 ilustra que quatro $(80,00 \%)$ das feridas apresentaram redução da área, sendo que uma ferida $(20,00 \%)$ cicatrizou completamente.

Quanto ao tecido de granulação, favorável à cicatrização, apresentou uma média de aumento de 46,80\% da 1a semana à 12a semana, conforme demonstra a Tabela 2.

Tabela 2. Distribuição das lesões quanto à quantidade de tecido de granulação. Niterói, RJ, Brasil, 2014.

\begin{tabular}{llllll}
\hline \multicolumn{6}{l}{ Evolução das lesões quanto à quantidade de tecido de granulação } \\
\hline & Lesão & D1 & D30 & D60 & D90 \\
\hline 1 & Lesão & $52,00 \%$ & $56,00 \%$ & $65,00 \%$ & $70,00 \%$ \\
\hline 2 & Lesão & $40,00 \%$ & $42,00 \%$ & $71,60 \%$ & $80,00 \%$ \\
\hline 3 & Lesão & $15,00 \%$ & $80,00 \%$ & $94,00 \%$ & $96,00 \%$ \\
\hline 4 & Lesão & $20,00 \%$ & $25,00 \%$ & $75,00 \%$ & $80,00 \%$ \\
\hline 5 & Lesão & $65,00 \%$ & $70,00 \%$ & $75,00 \%$ & Cicatrizou \\
\hline
\end{tabular}

Fonte: dados da pesquisa.

O tecido de epitelização, que representa ofechamento da ferida, apresentou média de aumento de 33,0\%. Ressalta-se que uma úlcera cicatrizou totalmente ao final do tratamento conforme a Tabela 3. 
Tabela 3. Distribuição das lesões quanto à quantidade de tecido de epitelização. Niterói, RJ, Brasil, 2014.

\begin{tabular}{lllll}
\hline \multicolumn{6}{l}{ Evolução das lesões quanto à quantidade de tecido de epitelização } \\
\hline Lesão & D1 & D30 & D60 & D90 \\
\hline Lesão 1 & $15,00 \%$ & $30,00 \%$ & $30,00 \%$ & $35,00 \%$ \\
\hline Lesão 2 & $20,00 \%$ & $20,00 \%$ & $30,00 \%$ & $40,00 \%$ \\
\hline Lesão 3 & $5,00 \%$ & $10,00 \%$ & $20,00 \%$ & $30,00 \%$ \\
\hline Lesão 4 & $5,00 \%$ & $5,00 \%$ & $10,00 \%$ & $15,00 \%$ \\
\hline Lesão 5 & $10,00 \%$ & $40,00 \%$ & $80,00 \%$ & Cicatrizou \\
\hline
\end{tabular}

Fonte: dados da pesquisa

Em relação à quantidade de exsudato, a maioria (três) das úlceras apresentou, na primeira visita do estudo, moderada quantidade de exsudato. Na última visita, duas das lesões possuíam pouca quantidade e uma estava cicatrizada (exsudato ausente). Além disso, ao final do tratamento, não havia nenhum paciente com grande quantidade de exsudato conforme o Quadro 1.

Quadro 1. Distribuição das lesões quanto à quantidade de exsudato. Niterói, RJ, Brasil, 2014.

\begin{tabular}{|c|c|c|c|c|}
\hline \\
\hline \multicolumn{5}{|c|}{\begin{tabular}{|l|l|l|l|} 
Lesão & Início & 30 dias & 60 dias
\end{tabular}} \\
\hline Lesão 1 & $\begin{array}{l}\text { Moderada } \\
\text { quantidade }\end{array}$ & $\begin{array}{l}\text { Moderada } \\
\text { quantidade }\end{array}$ & $\begin{array}{l}\text { Moderada } \\
\text { quantidade }\end{array}$ & $\begin{array}{l}\text { Pouca } \\
\text { quantidade }\end{array}$ \\
\hline Lesão 2 & $\begin{array}{l}\text { Pouca } \\
\text { quantidade }\end{array}$ & Pouca quantidade & $\begin{array}{l}\text { Pouca } \\
\text { quantidade }\end{array}$ & $\begin{array}{l}\text { Pouca } \\
\text { quantidade }\end{array}$ \\
\hline Lesão 3 & $\begin{array}{l}\text { Moderada } \\
\text { quantidade }\end{array}$ & $\begin{array}{l}\text { Moderada } \\
\text { quantidade }\end{array}$ & $\begin{array}{l}\text { Moderada } \\
\text { quantidade }\end{array}$ & $\begin{array}{l}\text { Moderada } \\
\text { quantidade }\end{array}$ \\
\hline Lesão 4 & $\begin{array}{l}\text { Grande } \\
\text { quantidade }\end{array}$ & $\begin{array}{l}\text { Moderada } \\
\text { quantidade }\end{array}$ & $\begin{array}{l}\text { Moderada } \\
\text { quantidade }\end{array}$ & $\begin{array}{l}\text { Moderada } \\
\text { quantidade }\end{array}$ \\
\hline Lesão 5 & $\begin{array}{l}\text { Moderada } \\
\text { quantidade }\end{array}$ & Pouca quantidade & \begin{tabular}{|l|} 
Pouca \\
quantidade
\end{tabular} & $\begin{array}{l}\text { Ausente } \\
\text { Cicatrizada }\end{array}$ \\
\hline
\end{tabular}

Fonte: dados da pesquisa.

A queixa de dor nas lesões de 4 pacientes foi mantida do início ao fim do tratamento. Nenhum apresentava edema na região perilesional e três pacientes queixavam-se de prurido nas lesões $(60,0 \%)$. Não foram evidenciadas reações adversas ao produto ao longo do tratamento. 


\section{Discussão}

Nos Estados Unidos, a taxa de prevalência de úlceras crônicas é de $2 \%$ da população geral ${ }^{(10)}$, no Brasil estima-se $3 \%{ }^{(11)}$.

Os resultados do estudo apresentam predominância de pacientes do sexo feminino e idosos. Estudos ${ }^{(12-13-14)}$ corroboram com esses resultados e citam como comorbidades predominantes a HAS e a IVC.

A HAS e o Diabetes Mellitus (DM) representam dois dos principais fatores de risco, contribuindo decisivamente para o agravamento deste cenário, em nível nacional ${ }^{(13)}$. Dos pacientes acompanhados no estudo, 40\%possui HAS e nenhum apresenta DM.

Diante deste panorama, identificou-se que as feridas crônicas estão presentes em grande parte na população adulta atingindo mais frequentemente as pessoas idosas, em decorrência do fato das feridas agudas não conseguirem seguir o processo de cicatrização sequencial e ordenado necessário ${ }^{(6)}$. Assim, o Brasil caminha rapidamente para um perfil demográfico mais envelhecido, caracterizado por uma transição epidemiológica, na qual as doenças crônicodegenerativas ocupam lugar de destaque.

Quanto à escolaridade, um participante havia concluído o ensino fundamental, um havia concluído o ensino médio e três concluíram o ensino superior. Este fato é relevante, pois quanto mais elevado o nível de instrução maior a facilidade em compreender as necessidades e orientações para o autocuidado.

$\mathrm{Na}$ distribuição dos pacientes pela ocupação, observa-se que todos possuem fonte de renda, sendo 3 participantes ativos e 2 aposentados. Este dado é relevante, pois dentre os pacientes que trabalham, muitos referem não conseguir fazer o repouso e a dieta adequada ao seu tratamento e muitos trabalham por muito tempo em pé, o que dificulta o processo de cicatrização, tendo em vista que uma das características das úlceras venosas é a estase e o edema, que se acumulam ao longo do $\mathrm{dia}^{(15)}$.

Clinicamente, os indivíduos com úlcera venosa apresentam dor e edema nas pernas, que pioram ao final do dia e podem ser aliviados com a elevação dos membros inferiores. De um modo geral, a úlcera venosa é uma ferida de forma irregular, superficial no início, mas pode se tornar profunda, com bordas bem definidas e comumente com exsudato amarelado. A região predominante deste tipo de úlcera é a porção distal dos membros inferiores, mas principalmente, na região do maléolo medial. A pele em torno da úlcera pode ser púrpura e hiperpigmentada (dermatite ocre), pelo extravasamento de hemácias na derme e depósito de hemossiderina no interior dos macrófagos ${ }^{(13)}$. A apresentação de lesões de etiologia venosa é mais comum nas extremidades, ao redor dos maléolos, principalmente o interno, terço inferior da perna ${ }^{(13)}$.

A SKTW é uma patologia rara que se manifesta tipicamente por malformações capilares cutâneas, anomalias venosas e/ou linfáticas, hipertrofia óssea e/ou dos tecidos moles associadas a malformações arteriovenosas. Atualmente, considera-se uma patologia congênita ${ }^{(17)}$. Estimase que as alterações venosas/linfáticas atinjam cerca de $70 \%$ e a hipertrofia dos membros apenas $65 \%$ dos casos. As manifestações clínicas desta patologia surgem, habitualmente, à nascença ou durante a infância ${ }^{(15)}$. Um participante da pesquisa apresentava esta síndrome.

Nos desfechos primários observados, verificou-se que uma ferida foi cicatrizada, com tempo médio para cicatrização de 90 dias, e as demais apresentaram taxa de redução da área das feridas de $34,00 \%, 30,00 \%, 12,00 \%$ e $11,00 \%$.

No início do tratamento, todas as lesões apresentaram alguma percentagem de tecido de granulação, três lesões apresentavam menos de $50,00 \%$ de tecido de granulação. Ao final de 90 dias, as cinco lesões apresentavam mais de $50,00 \%$, além de uma lesão estar completamente cicatrizada. No que tange a presença de tecido de epitelização, no início do tratamento,todas as lesões apresentavam menos de $20,00 \%$ de tecido de epitelização no leito da úlcera. Ao final de 90 dias, 3 lesões apresentavam pouco mais de $30,00 \%$.

Estudo $^{(6)}$ mostra que a característica do tecido presente na ferida é um importante indicador do estágio da cicatrização alcançado ou de qualquer complicação que possa estar presente. O tecido de granulação, fundamental para o processo de 
reparo tecidual fisiológico, é um tecido vermelho, brilhante, composto basicamente por vasos sanguíneos e colágeno, o topo dos arcos capilares faz com que a superfície tenha aparência granular, de onde vem seu nome.

O tecido epitelizado apresentado nas bordas é fino e róseo e sua orientação se dá em direção ao centro da lesão, levando a contração e consequente fechamento da lesão(6). A cicatrização de feridas é processo complexo intermediado por sinais de interação molecular envolvendo mediadores e eventos celulares, o que é seguido por recrutamento de células mesenquimais, proliferação e regeneração da matriz extracelular. O processo de cicatrização é uma resposta da imunidade inata para restauração da integridade do tecido, e é regulado por um padrão de eventos que incluem: coagulação, inflamação, formação de tecido de granulação, epitelização e remodelamento tecidual. Estes eventos são mediados e modulados por citocinas e fatores de crescimento que estimulam e modulam tais atividades celulares ${ }^{(16)}$.

Outro sintoma importante de ser avaliado é a dor, que nos pacientes do estudo foi frequente e de intensidade variável, não sendo influenciada pelo tamanho da úlcera. Em relação ao edema, nenhum participante apresentou, e três pacientes queixavam-se de prurido nas lesões.

Como contribuições deste estudo têm-se a assistência, ensino e a pesquisa. Acredita-se que a compreensão da realidade estudada seja um dos caminhos para aprimorar o cuidado conferido no serviço público de saúde, contribuindo para a excelência da assistência. A principal limitação foi o recrutamento dos pacientes e o número reduzido dos mesmos, o longo tempo dispensado na realização do procedimento e a impossibilidade de realização de inferências estatísticas sólidas por tratar-se de uma série de casos.

\section{Conclusão}

Foi evidenciado que o PRP pode ser bem-sucedido na cicatrização de feridas que não fecham por outras técnicas de tratamento. 0 estudo apresentou como resultados: o aumento da velocidade de debridamento de tecidos desvitalizados; a melhora no tipo de tecido no leito da ferida, pois após 90 dias uma ferida cicatrizou e as demais apresentaram mais de $50 \%$ de tecido de granulação e epitelização; além da diminuição do tamanho em $100 \%$, 30\%, 34\%, 12\%, 11\%.

O método de elaboração do PRP foi executado por enfermeiras treinadas, e sua preparação e realização de curativos levaram em média 60 minutos, após a coleta de sangue. Ressalta-se a importância do desenvolvimento de tecnologias em saúde que tragam benefícios e segurança ao paciente com lesões, melhorando sua qualidade de vida. Dessa forma, espera- se que os dados da pesquisa subsidiem a realização de novos estudos com o aumento da amostra.

\section{Referências}

1- Lund H, CurtinJ. Management of a nonhealing postoperative wound using a bacteria and fungi-binding mesh. WoundsInternational, 2014;5(4):20-22.

2- Sebastian KMS, Lobato I, Hernández I, Burgos-Alonso N,Gomez-Fernandez MC, López JL, Rodríguez B, et al. Efficacy and safety of autologous platelet rich plasma for the treatment of vascular ulcers in primary care: phase III study. BMC Family Practice. 2014;15:1-8.

3- Malaquias SG, Bachion MM,Sant'Ana SMSC, Dallarmi, CCB, Junior RSL, Ferreira PS.Pessoas com úlceras vasculogênicas em atendimento ambulatorial de enfermagem: estudo das variáveis clínicas e sociodemográficas.RevEscEnferm USP. 2012;19(5):535-541.

4- Dias TYAF, Costa IKF, Salvotti $\wedge$ G, Mendes CKTT, Torres GV.Influênc isistência e características clínica na ym.....ude de vida de portadores de úlcera venosa.Acta Paul Enferm. 2013;26(6):529-34.

5- Martinez-Zapata MJ, Martí-Carvajal AJ, Solà I, Expósito JA, Bolíbar I, Rodríguez L, Garcia J. Autologousplatelet-rich plasma 
for treatingchronicwounds. The Cochrane Library. 2012;17(10).

6- Oliveira BGRB, Nogueira GA, Carvalho MR, Abreu AM. Caracterização dos pacientes com úlcera venosa acompanhados no Ambulatório de Reparo de Feridas.RevEletr Enf.2012; 14(1):156-63.

7- Boswell SG, Cole BJ, Sundman EA, Karas V, Fortier LA. Platelet-rich plasma: a milieu of bioactive factors. Arthroscopy. 2012;28(3):429-439.

8- Souza MV,Pinto JO,Costa MM, Santos EC, Garcia SLR, Oliveira LL. Quantificação de fatores de crescimento na pele de equinos tratada com plasma rico em plaquetas. Pesq Vet Bras. 2014;34(6):599612.

9- Demidova-Rice TN,Wolf L, Deckenback J, Hamblin, MR, Herman IM. Human plateletrich plasma and extracellular matrix derived peptides promote impaired cutaneous wound healing in vivo. PLoS ONE. 2012;7(2):e32146.

10- PINTO JMN,Pizani NS1, Kang HC1, Silva LA1. Application of platelet-rich plasma in the treatment of chronic skin ulcer - case report. An Bras Dermatol. 2014;89(4):63840.

11- Fife CE, Carter MJ. Wounds care outcomes and associated cost among patients treated in US outpatient wound centers: data from US wound registry. Wounds. 2012;24(1):10-17.

12- Reis DB, Perez GA, Zuffi FB, Ferreira LA, Pogetto MTD. Cuidados às pessoas com úlcera venosa: percepção dos enfermeiros da estratégia de saúde da família. REME.2012;17(1):107-111.

13- Oliveira FP, Chrizóstimo MM, Barreto BMF, Brandão ES, Brum AKR, Oliveira BGRB.
Ação antimicrobiana do fator de crescimento epidérmico em feridas: revisão integrativa. Rev Enferm Atual. 2016.

14- Oliveira BGRB, Castro JBA, Granjeiro JM. Panorama epidemiológico e clínico de pacientes com feridas crônicas tratados em ambulatório. RevEnferm UERJ. 2013;21(1): 612-7.

15-Dufau JP, Le Tourneau A, Audouin J, Delmer A, Diebold J. Isolated diffuse hemangiomatosis of the spleen with Kasabach-Merritt-like Syndrome. Histopathology. 1999;35:33744.

16- Pinto JMN, Pizani NS, Kang HC, Silva LAK. Aplicação de plasma rico em plaquetas no tratamento de úlcera cutânea crônicarelato de caso. AnBrasDermatol. 2014; 89(4):638-40. 